Received: 05.07 .2018

Revised: 27.12 .2018

Accepted: 15.02 .2019

DOI: $10.17804 / 2410-9908.2019 .1 .070-075$

\title{
A STUDY OF FATIGUE PROCESSES IN THE MATERIAL OF THE COMPRESSOR BLADES OF A GAS TURBINE ENGINE AFTER LONG-TERM OPERATION
}

\author{
I. N. Tsareva ${ }^{\text {a)* }}$, O. B. Berdnik ${ }^{\text {b) }}$, and S. V. Kirikov ${ }^{\text {c) }}$ \\ Mechanical Engineering Research Institute - \\ Branch of Federal Research Center Institute of Applied Physics of the Russian Academy of Sciences, \\ 85 Belinskogo St., Nizhny Novgorod, 603024, Russian Federation \\ a) (iD https://orcid.org/0000-0002-2538-427X @irichatsareva@ mail.ru; \\ b) (iD https://orcid.org/0000-0003-4100-9493 @ berdnik80@ mail.ru; \\ c) iD https://orcid.org/0000-0002-5039-2271 ख ksv.kirikov@yandex.ru \\ *Corresponding author: E-mail: npktribinika@yandex.ru \\ Address for correspondence: Belinskogo St., 85, 603024, Nizhny Novgorod, Russian Federation \\ Tel.: +7 (831) 4320301
}

The paper studies the microstructure and mechanical properties of the material of an axial compressor incorporated in a gas pumping unit after long-term operation. It is known that, during long-term operation, fatigue damage accumulates in the material. This is due to the simultaneous impact of vibration and mechanical loads on the material of the blades, as well as the influence of air flow at elevated temperatures. In order to determine the stage of fatigue, the microstructure and mechanical properties of the material (steel 20Kh13) were studied. Such changes as the formation of microporosity, the disintegration of sub-grained blocks of the $\alpha$-Fe phase, and the coagulation of the carbide phase are found in the material structure. The accumulation of fatigue damages is most pronounced in the material of the 5th stage blades and it is manifested in the increasing microhardness of the airfoil surface and decreased tensile strength near the blade root.

Keywords: gas turbine engine, compressor blades, microstructure, porosity, dislocations, hardness, strength.

\section{Introduction}

Working blades of compressors are critical parts of gas turbine engines of gas pumping units. They are made of chrome stainless steel and operated under conditions of elevated temperatures (up to $400{ }^{\circ} \mathrm{C}$ ), erosive effects of air flow, vibration and cyclic loads. The main types of damage to compressor blades during long-term operation are erosion and corrosion wear of the working surface, as well as fatigue failure. The analysis of the blade material with different operating times is an urgent task for studying fatigue processes and predicting the residual life of the parts [1]. Previously, we studied the condition the material compressor blades, which had operated within the assigned lifetime (with a run time of 50000 to 60000 hours) [2]. The purpose of this study is to study the fatigue processes in stainless chromium steel at the maximum permissible operating time of 110000 hours.

\section{Material and methods}

The studies were carried out on samples cut from different areas of the blade root and feather, as well as directly on the working surface of the compressor blades of different stages of a GTK-10I gas compressor unit. The elemental composition of the blade material was determined by 
the atomic-emission method. The microstructure of the material was analyzed using an Axio Observer inverted optical microscope. The porosity of the material was determined from the images of the microstructure using the Goud fase program. The phase composition and substructure of the blade material were examined by X-ray diffraction analysis using a Dron-3M diffractometer $\left(\mathrm{Cu}-\mathrm{K}_{\alpha}\right.$-radiation, Bragg-Brentano survey method). The parameters of the substructure (the size of the subgrain blocks and the magnitude of microdeformations in them) were determined by the method of approximations from the physical broadening of the diffraction lines (011) and (022) of $\alpha$-Fe. The density of dislocations at the boundaries and inside the subgrain blocks was evaluated by the formulas [3]

$$
\begin{gathered}
\rho_{L}=\frac{3}{D^{2}} ; \\
\rho_{\varepsilon}=\frac{k(2 \varepsilon)}{b},
\end{gathered}
$$

where $\rho_{L}$ is dislocation density at the boundaries of the subgrain blocks, $D$ is the size of the subgrain blocks, $\rho_{\varepsilon}$ is dislocation density inside the subgrain blocks, $\square \square \varepsilon$ is the value of microdeformation, $k$ is the proportionality coefficient ( $k=16.1$ for the cubic lattice), $b$ is the size of the Burgers vector.

The mechanical properties of the material were determined using a tensile test. In addition, the tensile strength of the material was determined using an MET-U1 ultrasonic hardness tester (for the indentation depth of $\sim 15 \mu \mathrm{m}$ ). Microhardness was measured on the working surface of the blades with a variable load on the indenter $(0.2$ to $2.0 \mathrm{~N})$ and on the cross-sections with the help of a PMT-3 microhardness tester.

\section{Results and discussion}

The compressor rotor blades are made of martensitic chromium stainless steel with the following elemental composition: $12.80 \% \mathrm{Cr}, 0.20 \% \mathrm{C}, 0.45 \% \mathrm{Ni}, 0.44 \% \mathrm{Mn}, 0.30 \% \mathrm{Si}$, $0.07 \% \mathrm{Mo}, 0.16 \% \mathrm{Cu}$. The phase composition of the blade material in the initial state is $\alpha-\mathrm{Fe}+\mathrm{Fe}_{3} \mathrm{C}$. A nickel-based protective galvanic coating is applied onto the surface of the blades in order to protect the blades from pitting corrosion. The material condition was studied on blades of the 0th stage, which operate at a minimum temperature $\left(\sim 100{ }^{\circ} \mathrm{C}\right)$, and on blades of the 5th stage, which are subjected to high temperature loads (up to $300{ }^{\circ} \mathrm{C}$ ), during operation. It was found by optical visual inspection that the coating on the surface of the blades is almost completely worn out after prolonged operation due to the erosive effect of a heated air flow (fig. 1). Numerous centers of pitting corrosion with a depth of 0.05 to $0.30 \mathrm{~mm}$ were found on the surface of the blades. The blades of all stages are prone to corrosion, and it is most pronounced in the zone near the exit edge. Some blades retain a small part of the coating near the exit edge (10 to $20 \%$ of the total area). There are single mechanical nicks on the edges. Metallographic analysis has shown that the microstructure of the material of the 0th-stage blade root, less affected by heating during operation, is close to the initial state of the 20Kh13 steel. It is sorbitic pearlite with a round-grained carbide phase $\left(\mathrm{Fe}_{3} \mathrm{C}\right)$, fig. 2 a. The microstructure of the airfoil material is similar to that in the state of the blade root material (fig. 2 b). In this case, there are processes of coagulation of the carbide phase, which are manifested locally. 


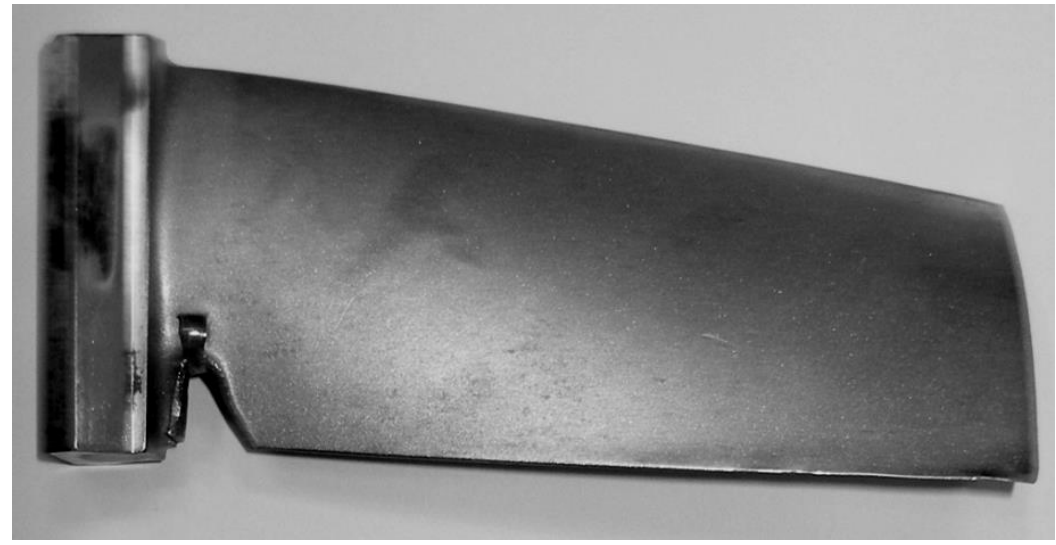

a

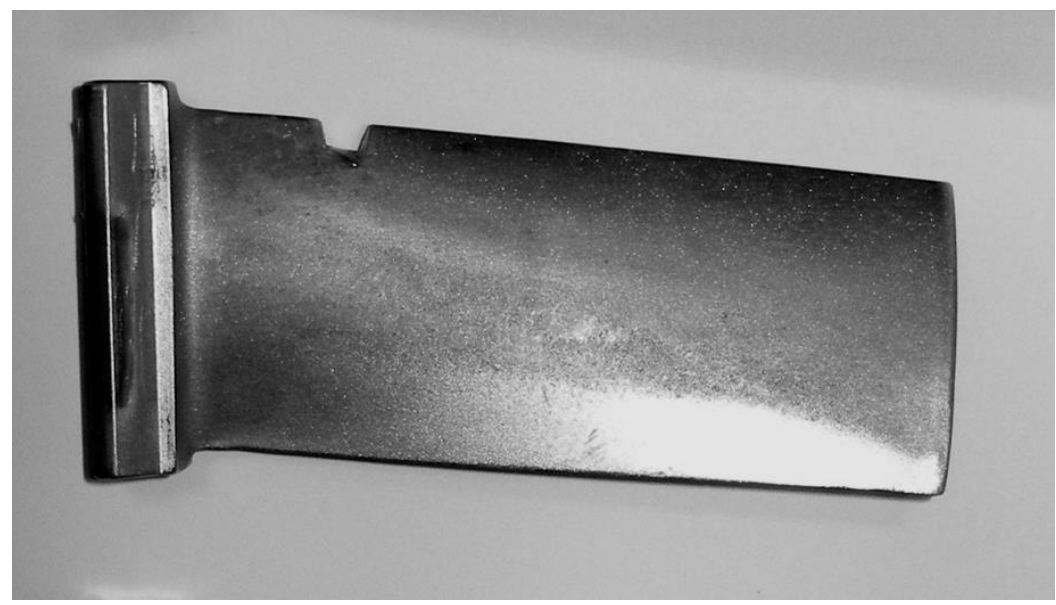

b

Fig. 1. The blades of the 0th (a) and 5th (b) stages after operation for 110,000 hours

After long-term operation, the microstructure of the material of the airfoil of the 5th-stage blade, subjected to the highest specific workloads during operation, is lamellar pearlite (fig. 3). Internal microporosity was found in the material of the blades, which is typical for the stage of damage accumulation in the development of fatigue processes. The porosity is $\sim 3 \%$ in the airfoil material and above $\sim 5 \%$ in the material of the blade root, which is a non-stagnant zone.

The material substructure parameters in different zones of the blade of the 5th stage were determined by X-ray diffraction (table). The material in the cross section of the root and airfoil parts is characterized by a large-block structure of $\alpha$-Fe grains with a dislocation density of $\sim 5.3 \cdot 10^{6} \mathrm{~cm}^{-2}$. The blade material in the most loaded zone (near the lock) is characterized by a finely dispersed substructure. Crushing of the grain blocks is a consequence of plastic deformation, and it is caused by the rearrangement of the dislocation configurations and the increasing (almost by an order of magnitude) dislocation density at the subgrain boundaries. It has been found that the changes in the substructure occur in the surface layer $(\sim 5$ to $15 \mu \mathrm{m}$ thick $)$ and that they leave unaffected the basis of the blade material.

The microhardness of the material of the working surface of the 0th-stage blades has a uniform depth distribution and ranges between 2.70 and 3.20 GPa. The microhardness of the 5th-stage blade material is $\sim 3.20 \mathrm{GPa}$ in the cross section, and this corresponds to the normalized values for the $20 \mathrm{Kh} 13$ steel. The high values $H_{200}=3.90 \mathrm{GPa}$ were obtained on the working surface, this being due to the crushed substructure of the material. According to the results of the mechanical tensile tests of samples cut from the airfoil of the 0th-stage blades, the tensile strength of the material is 746.4 MPa, with a specific elongation of $13.7 \%$.

Tsareva I. N., Berdnik O. B., Kirikov S. V. A study of fatigue processes in the material of the compressor blades of a gas turbine engine after long-term operation // Diagnostics, Resource and Mechanics of materials and structures. - 2019. - Iss. 1. - 
The obtained data characterize the state of the inner layers of the blade material. Since the aging process usually develops in the surface layer of the blades, ultimate strength was measured by an ultrasonic hardness tester directly on the working surface. The values of the tensile strength of the root of the 0th-stage blades (900 to $990 \mathrm{MPa}$ ) are close to the normalized value for the $20 \mathrm{Kh} 13$ steel $(\sim 950 \mathrm{MPa})$. This is due to the fact that the blade root is less subjected to cyclic loads during operation.

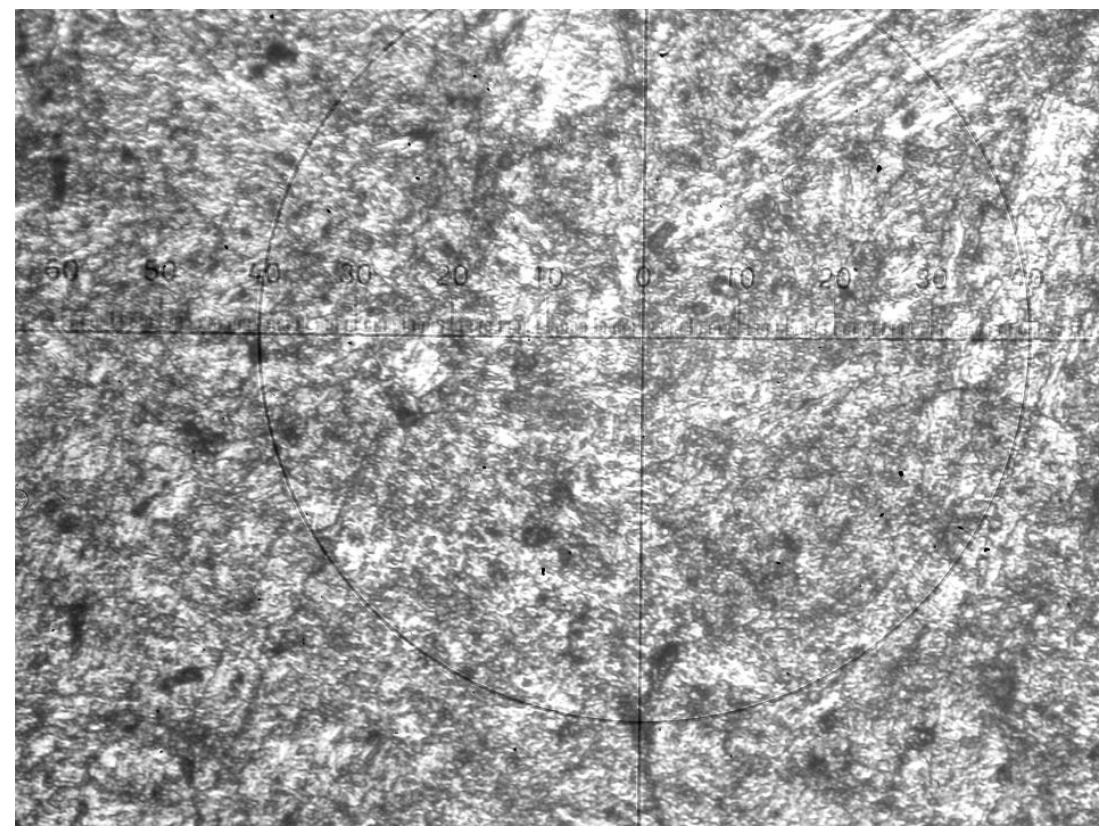

a

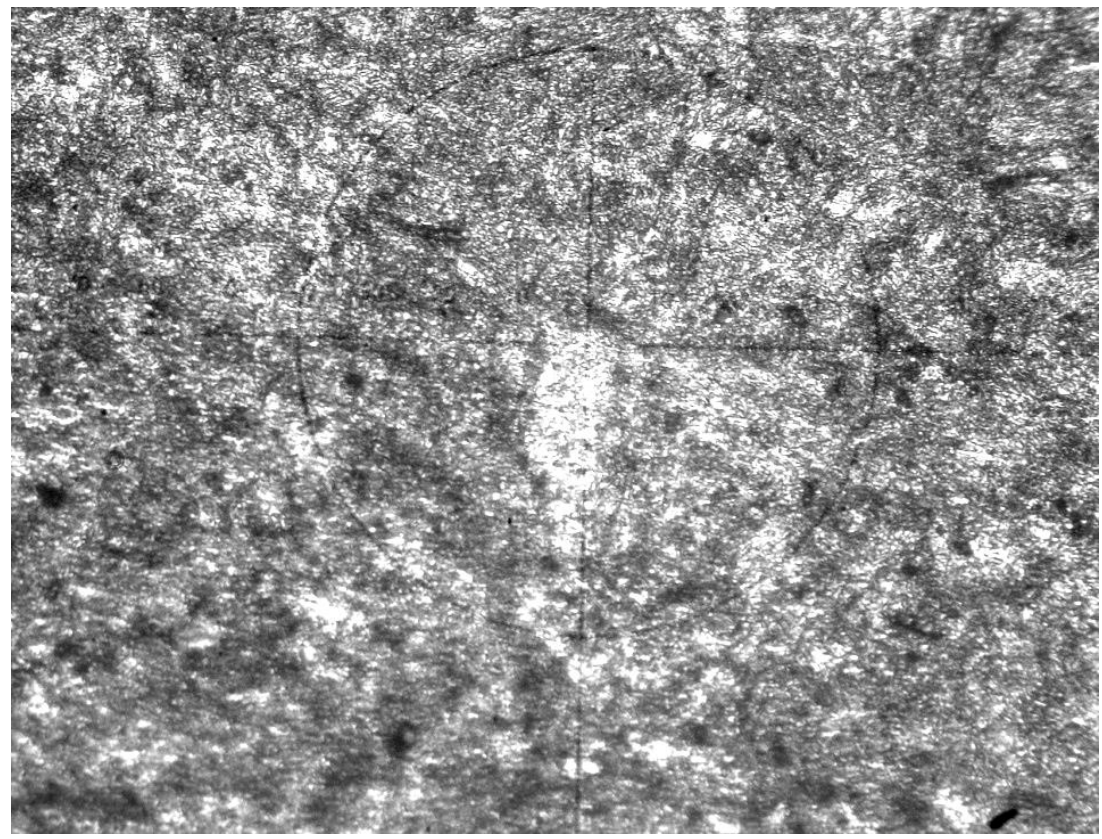

$\mathrm{b}$

Fig. 2. Material microstructure in the root (a) and airfoil (b) of the 0th-stage working blade, $\times 500$ 


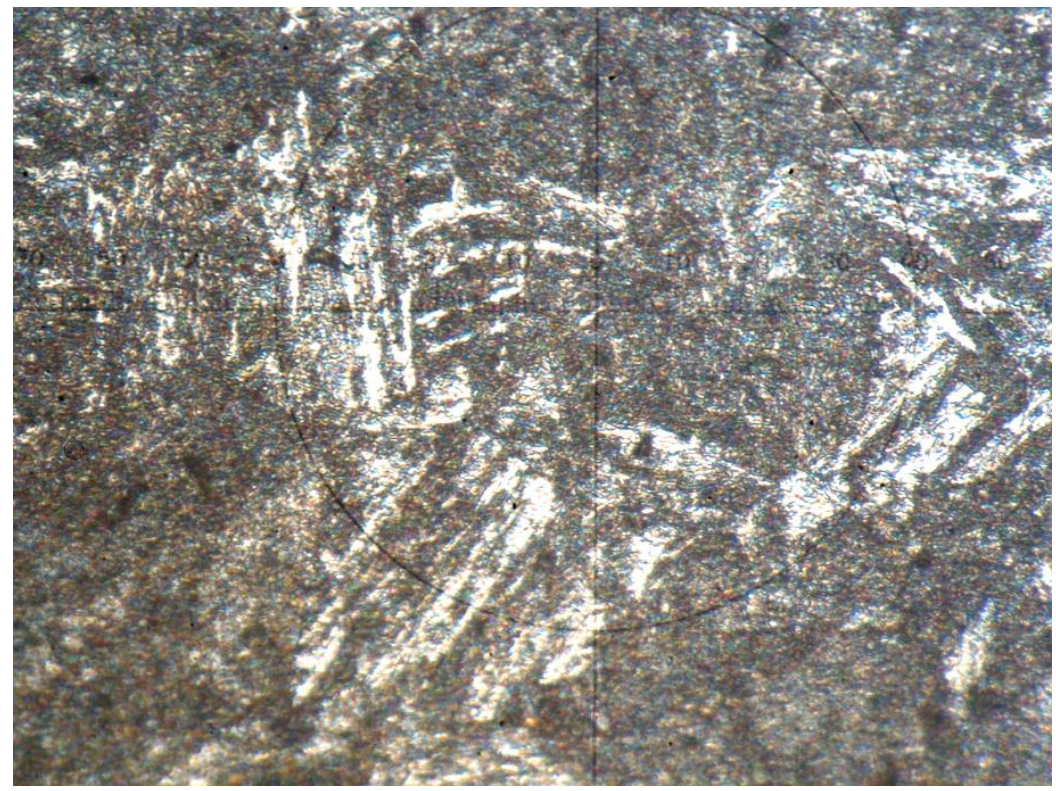

Fig. 3. Material microstructure in the airfoil of the 5 th-stage working blade, $\times 500$

The $\alpha$-Fe substructure parameters of the 5th-stage blade material

\begin{tabular}{|c|c|c|c|c|}
\hline $\begin{array}{c}\text { Analyzed } \\
\text { area }\end{array}$ & $\begin{array}{c}\text { Subgrain size } \\
D, \mathrm{~nm}\end{array}$ & $\begin{array}{c}\text { Microstrain value } \\
\delta, 10^{-4}\end{array}$ & $\begin{array}{c}\text { Dislocation den- } \\
\text { sity } \rho_{L} \text { at the } \\
\text { subgrain bound- } \\
\text { aries, } \mathrm{m}^{-2}\end{array}$ & $\begin{array}{c}\text { Dislocation } \\
\text { density } \rho_{\varepsilon} \\
\text { inside the } \\
\text { grains, } \mathrm{m}^{-2}\end{array}$ \\
\hline $\begin{array}{c}\text { Cross section } \\
\text { of the blade root }\end{array}$ & 500 & 8.2 & $10^{5}$ & $5.3 \cdot 10^{6}$ \\
\hline $\begin{array}{c}\text { Cross section } \\
\text { of the airfoil }\end{array}$ & 500 & 8.2 & $10^{5}$ & $5.3 \cdot 10^{6}$ \\
\hline $\begin{array}{c}\text { Working surface } \\
\text { of the airfoil }\end{array}$ & 180 & 4.1 & $9.2 \cdot 10^{5}$ & $1.3 \cdot 10^{6}$ \\
\hline
\end{tabular}

The ultimate strength on the working surface of the blade airfoil near the blade root is reduced (740 to $780 \mathrm{MPa}$ ). In the airfoil of the 5th-stage blades, in the same zone, the lowest tensile strength values (620 to $720 \mathrm{MPa})$ are obtained. The decrease in the strength characteristics of the blade material in the area near the lock is due to the effect of severe vibromechanical loading.

\section{Conclusion}

From the analysis of the state of the material of compressor blades having operated for $\sim 110,000$ hours, it has been found that the fatigue processes are most pronounced in the material of 5th-stage blades, which are subject to the highest thermomechanical loads. They manifest themselves in the form of coagulation of the carbide phase and accumulation of dislocations at the $\alpha-\mathrm{Fe}$ subgrain boundaries. This increases surface microhardness and decreases ultimate strength in the zone near the blade root.

\section{Acknowledgment}

The work was carried out within the framework of the state assignment for the IAP RAS for conducting basic research in 2013-2020, theme No. 0035-2014-0401 (State registration number 01201458049). 


\section{Reference}

1. Zheganina I.P., Morozov L.V. Definition of pre-destruction diagnostic signs on condition of surface layers of heat resistant nickel alloys Determination of diagnostic signs of predestruction on a condition of blankets of heat resisting nickel alloys. VIAM, 2015, no. 4. DOI: 10.18577/2307-6046-2015-0-4-4-4. Available at: http://www.viam-works.ru (accessed 24.12.2015). (In Russian).

2. Tsareva I.N., Berdnik O.B., Krivina L.A., Fel Ya.A. The way to estimate engineering state of compressor's working blades made of EI961 alloy for gas-turbine power plant-45-3. In: Prikladnaya mekhanika i tekhnologii mashinostroeniya. Sbornik nauchnykh trudov (Applied Mechanics and Machinery Manufacturing Technologies. Collection of Scientific Papers), Nizhni Novgorod, Intelservis Publ., 2013, no. 1 (22), pp. 37-42. (In Russian).

3. Palatnik L.S., Fuks M.Ya., Kosevich V.M. Mekhanizm obrazovaniya i substruktura kondensirovannykh plenok (Mechanism of Formation and Substructure of Condensed Films). M., Nauka Publ., 1972. (In Russian). 